\title{
On the generation of solitary waves observed by Cluster in the near-Earth magnetosheath
}

\author{
J. S. Pickett ${ }^{1}$, L.-J. Chen ${ }^{1}$, S. W. Kahler ${ }^{1}$, O. Santolík ${ }^{1,2}$, M. L. Goldstein ${ }^{3}$, B. Lavraud ${ }^{4}$, P. M. E. Décréau ${ }^{5}$, R. Kessel ${ }^{3}$, \\ E. Lucek ${ }^{6}$, G. S. Lakhina ${ }^{7}$, B. T. Tsurutani ${ }^{8}$, D. A. Gurnett ${ }^{1}$, N. Cornilleau-Wehrlin ${ }^{9}$, A. Fazakerley ${ }^{10}$, H. Rème ${ }^{11}$, and \\ A. Balogh ${ }^{6}$ \\ ${ }^{1}$ Department of Physics and Astronomy, The University of Iowa, Iowa City, IA, USA \\ ${ }^{2}$ Faculty of Mathematics and Physics, Charles University, Prague, Czech Republic \\ ${ }^{3}$ NASA Goddard Space Flight Center, Greenbelt, MD, USA \\ ${ }^{4}$ Los Alamos National Laboratory, Los Alamos, NM, USA \\ ${ }^{5}$ LPCE et Université d'Orléans, Orléans, France \\ ${ }^{6}$ The Blackett Laboratory, Imperial College, London, UK \\ ${ }^{7}$ Indian Institute of Geomagnetism, Colaba, Mumbai, India \\ ${ }^{8}$ Jet Propulsion Laboratory, California Institute of Technology, Pasadena, CA, USA \\ ${ }^{9}$ CETP/UVSQ, Vélizy, France \\ ${ }^{10}$ Mullard Space Science Laboratory, University College London, Holmbury St. Mary, UK \\ ${ }^{11}$ CESR, 9 ave. du Colonel Roche, 32018 Toulouse Cédex 4, France
}

Received: 18 October 2004 - Revised: 19 January 2005 - Accepted: 20 January 2005 - Published: 2 February 2005

Part of Special Issue "Advances in space environment turbulence"

\begin{abstract}
Through case studies involving Cluster waveform observations, solitary waves in the form of bipolar and tripolar pulses have recently been found to be quite abundant in the near-Earth dayside magnetosheath. We expand on the results of those previous studies by examining the distribution of solitary waves from the bow shock to the magnetopause using Cluster waveform data. Cluster's orbit allows for the measurement of solitary waves in the magnetosheath from about $10 R_{E}$ to $19.5 R_{E}$. Our results clearly show that within the magnetosheath, solitary waves are likely to be observed at any distance from the bow shock and that this distance has no dependence on the time durations and amplitudes of the solitary waves. In addition we have found that these same two quantities show no dependence on either the ion velocity or the angle between the ion velocity and the local magnetic field direction. These results point to the conclusion that the solitary waves are probably created locally in the magnetosheath at multiple locations, and that the generation mechanism is most likely not solely related to ion dynamics, if at all. To gain insight into a possible local generation mechanism, we have examined the electron differential energy flux characteristics parallel and perpendicular to the magnetic field, as well as the local electron plasma and cy-
\end{abstract}

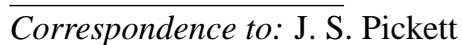

(pickett@uiowa.edu) clotron frequencies and the type of bow shock that Cluster is behind, for several time intervals where solitary waves were observed in the magnetosheath. We have found that solitary waves are most likely to be observed when there are counterstreaming ( $\sim$ parallel and anti-parallel to the magnetic field) electrons at or below about $100 \mathrm{eV}$. However, there are times when these counterstreaming electrons are present when solitary waves are not. During these times the background magnetic field strength is usually very low $(<10 \mathrm{nT})$, implying that the amplitudes of the solitary waves, if present, would be near or below those of other waves and electrostatic fluctuations in this region making it impossible to isolate or clearly distinguish them from these other emissions in the waveform data. Based on these results, we have concluded that some of the near-Earth magnetosheath solitary waves, perhaps in the form of electron phase-space holes, may be generated locally by a two-stream instability involving electrons based on the counterstreaming electrons that are often observed when solitary waves are present. We have not ruled out the possibility that the solitary waves could be generated as a result of the lower-hybrid Buneman instability in the presence of an electron beam, through the electron acoustic mode or through processes involving turbulence, which is almost always present in the magnetosheath, but these will be examined in a more comprehensive study in the future. 


\section{Introduction}

The multi-spacecraft Cluster mission is providing insight into numerous geophysical processes occurring in the vicinity of Earth (e.g., refer to Ann. Geophys., special issue Volume 19, Nos. 10/12, 2001 and Volume 22, No. 7, 2004 focused on Cluster). Among the new results provided by Cluster are those devoted to or including observations of electrostatic solitary waves in the near-Earth magnetosheath, auroral zone/near-Earth plasma sheet and magnetopause (Pickett et al., 2003, 2004a, b; Cattell et al., 2003), and in association with SLAMS (Short Large Amplitude Magnetic Structures) observed in the quasi-parallel foreshock region (Behlke et al., 2004). The magnetosheath solitary waves are of particular interest because their pulse time durations are significantly shorter than those found in the other regions around Earth (Pickett et al., 2004b). These isolated pulses, primarily bipolar (one positive peak and one negative peak) and tripolar (two positive peaks and one negative peak, or vice versa), are of the order of tens to a few hundreds of $\mu \mathrm{s}$ in duration in the near-Earth magnetosheath. This is in contrast to the distant magnetosheath where the solitary waves observed by Geotail were found to have pulse widths of order 1-2 ms (Kojima et al., 1997). However, it is doubtful that the plasma wave instrument on Geotail would have measured solitary waves with time durations of $10 \mathrm{~s}$ to $100 \mathrm{~s}$ of $\mu$ s since the instrument had a sampling frequency of $12 \mathrm{kHz}$ and a bandwidth of only $10 \mathrm{~Hz}$ to $4 \mathrm{kHz}$.

The generation of solitary waves and the role of solitary waves in other geophysical processes taking place in the magnetosheath have not been explored in depth. Understandably, it is extremely difficult to untangle all of the wave modes observed in the magnetosheath because the spectra, both at low and high frequencies, are usually dominated by turbulence or turbulent-like features, both in the wave electric and wave magnetic fields. Some progress on uncovering the wave modes in the magnetosheath low frequency measurements has led to some quite surprising results using the wave telescope and k-filtering techniques, e.g., see Glassmeier et al. (2001) and Sahraoui et al. (2003). The latter have found that at any one frequency, there can be a superposition of more than one mode, e.g., dominant mirror mode and Alfvén and slow modes.

At higher frequencies, the magnetosheath spectrum is usually dominated by what was previously termed Broadband Electrostatic Noise (BEN). Rodriguez (1979) used plasma wave measurements from the $\operatorname{Imp} 6$ satellite to characterize $\mathrm{BEN}$ observed in the magnetosheath at $R_{E}<30$ (similar to Cluster) as being almost continuously present with broadband $(20 \mathrm{~Hz}$ to $70 \mathrm{kHz}) \mathrm{rms}$ field intensities. They found that the BEN usually consisted of three components: 1) a high frequency ( $\geq 30 \mathrm{kHz}$ ) component peaking at the plasma frequency, 2) a low frequency component with a broad intensity maximum below the nominal ion plasma frequency, and 3) an intermediate component in the range from the ion plasma frequency up to the electron plasma frequency. We now know that part of the BEN, at least some of the higher frequency part extending up to as much as $40-60 \mathrm{kHz}$, which is also near or higher than the typical electron plasma frequency in the magnetosheath, is a result of the isolated solitary waves imbedded in the wave field as detailed in Pickett et al. (2003). The remainder of the wave electric field usually consists of waves with frequencies around $1-3 \mathrm{kHz}$, the mode identification of which has still not been made, as well as short bursts of lion roars around a few Hundred $\mathrm{Hz}$ (also clearly seen in the wave magnetic field data) (Tsurutani et al., 1982; Maksimovic et al., 2001) and electron cyclotron waves around the local electron cyclotron frequency.

The primary purpose of this paper is to report the results of a survey in which we characterize the solitary waves observed by Cluster within the magnetosheath from the bow shock to the magnetopause in terms of numbers, amplitude and time duration. Complementary to this we look at these same quantities in relation to the local ion velocity and the angle of the ion velocity to the magnetic field direction. By analyzing these characterizations, we will be in a position to argue whether these solitary waves are being locally produced and whether their generation is controlled by ion dynamics. The outline of our paper is as follows. The primary instrumentation involved in making the measurements pertinent to this study will first be discussed. This will be followed by the presentation of a sample event in which many solitary waves are observed in the magnetosheath, with supporting wave, electron density, ion, electron and magnetic field data also being provided. The results of the survey discussed above from a few magnetosheath passes are given in the next section. This is followed by an analysis of the survey results and a discussion of the implications of those results. We end with a summary of our results and conclusions.

\section{Instrumentation}

In order to observe the short time duration bipolar and tripolar pulses (solitary waves) in the near-Earth magnetosheath, we require a waveform receiver with wide bandwidth and high time resolution. Cluster's Wideband (WBD) Plasma Wave Receiver (Gurnett et al., 1997, 2001) is particularly well-suited for these measurements since one of its modes is a $77 \mathrm{kHz}$ bandpass filter with a sampling frequency of $219.5 \mathrm{kHz}$ which is achieved primarily through the use of downlinking the data directly to a receiving station on the ground. In this mode the waveforms are continuously sampled for $\sim 9.9 \mathrm{~ms}$, followed by a gap of $69.5 \mathrm{~ms}$, comprising a total cycle time of $79.4 \mathrm{~ms}$. Because of viewing limitations of the receiving ground stations, the typical measurement period for any WBD operation is on the order of $1-4 \mathrm{~h}$. Thus, WBD data are not usually obtained from bow shock to magnetopause in one data interval.

WBD's measurements are made along one axis only, that being within the spin plane of the spacecraft. Cluster WBD was hard wired to measure only the average potential between the two spheres on one antenna, thus preventing the possibility of making interferometry measurements on just 
one spacecraft. Interferometry measurements are typically made by comparing the two waveforms obtained by measuring the potential between each sphere and the spacecraft where the spheres are located at or near the end of a single electric field antenna boom. Since WBD cannot be operated in an interferometry mode, this means that the instrument on one spacecraft is unable to provide velocities of the solitary waves, and thus their parallel widths, as has been done for several studies found in the literature (e.g., Franz et al., 1998; Ergun et al., 1998; Cattell et al., 1999). On the other hand, most waveform receivers that make interferometry measurements in the magnetosheath do not have the capability of the wider bandwidth required to see such short time duration pulses, or if they do, take them in short duration bursts that do not allow for continuity of measurement across large expanses of the magnetosheath. Although Cluster WBD could carry out an interferometry measurement by using two separate spacecraft and noting the propagation time of a solitary wave from one spacecraft to the next, we believe the distances between the two spacecraft are far too great based on our initial attempts to do this. The reader is referred to Pickett et al. (2004a) for a discussion of a study where limited success was achieved in doing this in the auroral zone.

The WBD instrument employs an AGC (automatic gain control), implemented in hardware, which provides $75 \mathrm{~dB}$ of selectable gain in addition to the $48 \mathrm{~dB}$ of instantaneous dynamic range for its measurements. Gain updates are made, as necessary, in order to keep the wave amplitude in the midrange of the instantaneous dynamic range. Gain is automatically added or subtracted in steps of $5 \mathrm{~dB}$, with a possible 15 steps ( 0 to $75 \mathrm{~dB})$. The gain update rate is always set at the fastest rate, i.e., every $1 / 10$ of one second, in the magnetosheath where short duration waves, such as solitary waves are often dominant. Receiver saturation can occur at the input at the $2 \mathrm{~V}$ level, providing a maximum peak-to-peak measurement of about $73 \mathrm{mV} / \mathrm{m}$, with $0 \mathrm{~dB}$ gain added and assuming an effective antenna length equal to the physical length of $88 \mathrm{~m}$, before clipping occurs at the output. To minimize nonlinear effects due to saturation of the amplifiers, the amplifiers were designed so that their maximum amplitude range is greater than the maximum range of the digitized signal output by the A/D converter. Thus waveforms may be clipped (not fully resolved by the 8 bits available) even though the receiver is not in saturation. The lowest amplitude measurement possible is on the order of $0.001 \mathrm{mV} / \mathrm{m}$ peak-to-peak. However due to the ever present electrostatic fluctuations that are found in the magnetosheath, the lowest possible solitary wave that could be resolved in the magnetosheath is usually on the order of $0.01 \mathrm{mV} / \mathrm{m}$ peak-to-peak.

The filters employed in the $77 \mathrm{kHz}$ bandwidth mode allow for the detection of pulses up to at least their RC-constant around 500 microseconds without confusing filter effects, such as slow responses to pulses, ringing of filters caused by pulses, and relaxation of filters after the pulse has passed, which have been thoroughly tested on the ground in order to substantiate that the pulses observed in space are geophysical (D. Kirchner, personal communication, 2004). Since the magnetosheath pulses are usually of the order of 0.01 to $1 \mathrm{mV} / \mathrm{m}$ (Pickett et al., 2004b, Fig. 3a), the likelihood that many pulses will be missed due to clipping or saturation of the receiver is relatively low. On the other hand, several pulses could be missed because of a low amplitude near the level of other electrostatic fluctuations, but we will discuss this point further when describing the actual measurements.

Supporting data for the WBD measurements are provided by the Cluster Fluxgate Magnetometer, FGM (Balogh et al., 1997), the Spectrum Analyzer of the Spatio-Temporal Analysis of Field Fluctuation experiment, STAFF (CornilleauWehrlin et al., 1997), the Whisper Sounder (Décréau et al., 1997), the Plasma Electron And Current Experiment, PEACE (Johnstone et al., 1997), and the Cluster Ion Spectrometry experiment, CIS (Rème et al, 2001). We use the magnetic field vector provided by the FGM experiment at spin resolution $(\sim 4 \mathrm{~s})$ to obtain total magnetic field strength, the value of the electron cyclotron frequency and the angle between the electric field antenna and the magnetic field. In its normal mode, the STAFF-SA experiment provides the 3axis magnetic (from tri-axial search coil magnetometers) and 2-axis electric (from the EFW electric field antennas) spectral matrix every $4 \mathrm{~s}$ in the frequency range $8 \mathrm{~Hz}$ to $4 \mathrm{kHz}$. From these data the wave normal and Poynting vectors can be obtained, as well as the ellipticity and planarity of the waves. The Whisper Sounder provides the electron plasma frequency, and thus electron density, every $52 \mathrm{~s}$ in the range of $2 \mathrm{kHz}$ to $80 \mathrm{kHz}$ by means of a relaxation sounder.

The CIS instrument consists of a Hot Ion Analyzer (HIA) and a time-of-flight COmposition and DIstribution Function analyzer (CODIF), which together provide the full threedimensional ion distribution with one spacecraft spin (about $4 \mathrm{~s})$ resolution. HIA has large energy and angular resolutions adequate for ion-beam and solar wind measurements, but without mass resolution. CODIF measures the distributions of the major ions with energies from about 0 to $40 \mathrm{keV} / \mathrm{e}$ with medium angular resolution. The PEACE instrument provides the electron distribution function in the energy range from $0.6 \mathrm{eV}$ to $\sim 26 \mathrm{keV}$ with an integration time of one satellite spin period $(\sim 4 \mathrm{~s})$. The PEACE instrument consists of two sensors: LEEA (Low Energy Electron Analyser) is designed to specialize in coverage of the very lowest electron energies (0.6-9.45 eV) and HEEA (High Energy Electron Analyser) is specialized in the upper end of the electron energy spectrum, although both sensors can cover the full energy range. In certain circumstances, PEACE can obtain a 3-D phase space distribution of particles at one-half spin resolution $(\sim 2 \mathrm{~s})$; however, the normal mode is spin resolution. Because the resolution of the electron and ion data are not sufficient to investigate the generation of the solitary waves at the micro scale (time scale of the solitary waves), we will take the macro scale approach to investigate their generation, i.e., analyze data over several minutes or hours duration from several events and look for consistent patterns.

Finally, interplanetary magnetic field and plasma data along with a 3-D bow shock model are used to determine quasi-perpendicular and quasi-parallel regions of Earth's 
(a)

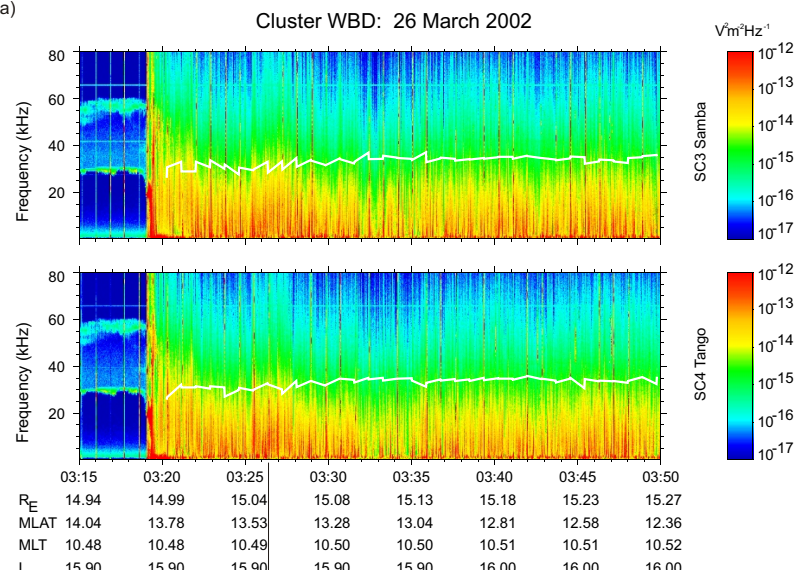

(b)

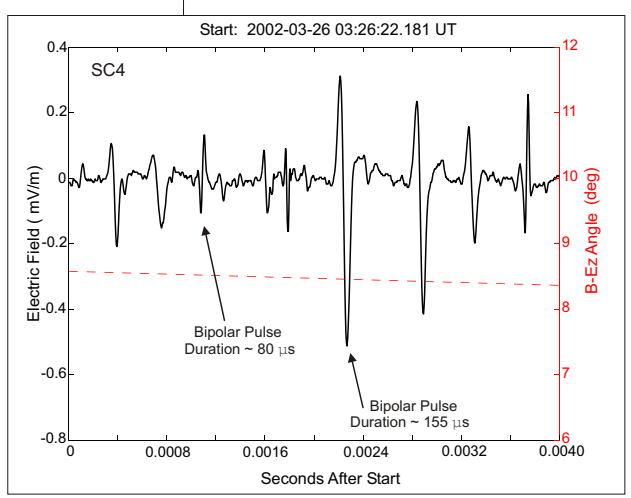

Fig. 1. (a) WBD spectrogram of plasma waves observed on 26 March 2002 as Cluster spacecraft 3 (top panel) and 4 (bottom panel) crossed into the magnetosheath at about 03:19 UT. Broadband waves up to and greater than the electron plasma frequency (white line) are observed in the magnetosheath on both spacecraft. (b) A $4 \mathrm{~ms}$ portion of the waveforms from which the spectrograms in (a) were produced. Note the short duration bipolar pulses seen throughout the $4 \mathrm{~ms}$ interval. These bipolar pulses are the primary reason for the broadbands seen in (a).

bow shock. Magnetic field data from the Wind MFI (Lepping et al., 1995) and ACE MAG (Smith et al., 1998) experiments were propagated to Earth using a delay time simply given by $\mathrm{t}=\mathrm{d} / \mathrm{v}_{s w}$, where $\mathrm{d}$ is the distance between Wind or ACE and Cluster and $\mathrm{v}_{s w}$ is the average solar wind speed in the $\mathrm{X}$-direction over the intervals of solitary waves from Wind SWE (Ogilvie et al., 1995) or ACE SWEPAM (McComas et al., 1998). A 3-D bow shock model was constructed from the original Fairfield (1971) 2-D model corrected for pressure and with axial symmetry assumed. If the angle, $\theta_{B n}$, between the local shock normal and IMF is $<45^{\circ}\left(>45^{\circ}\right)$ the region is quasi-parallel (quasi-perpendicular).

\section{Sample event}

Figure 1a shows a 35 -min spectrogram of data obtained by WBD on 26 March 2002 on two of the four Cluster spacecraft (SC3 and SC4) as they crossed the bow shock at about 03:19 UT from the solar wind into the magnetosheath at

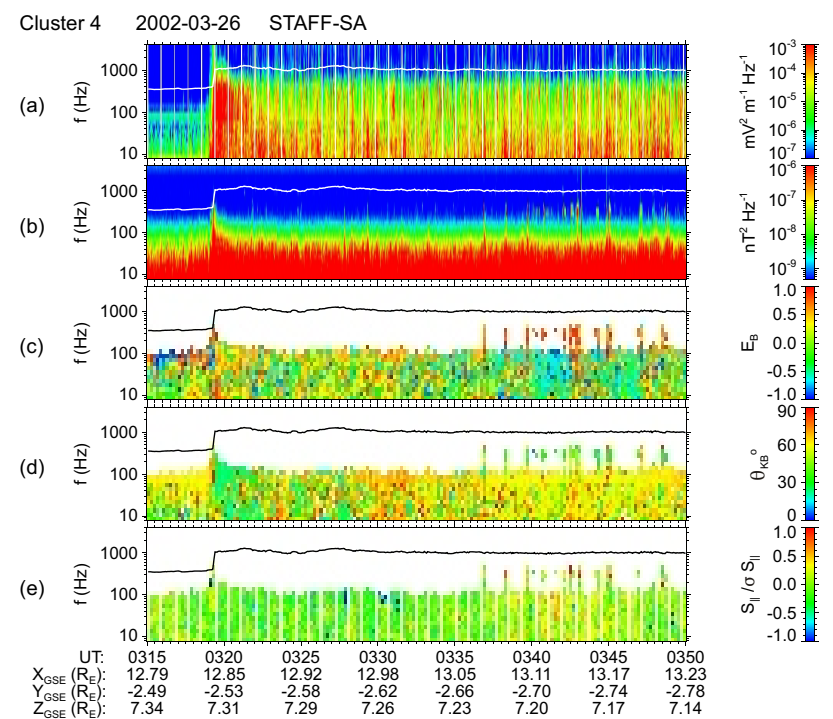

Fig. 2. STAFF-SA data for spacecraft 4 for the same time period as shown in Fig. 1. (a) sum of the electric power spectral density from the orthogonal electric field antennas, (b) sum of the magnetic power spectral density from the three orthogonal magnetic field antennas, (c) estimate of the ratio of lengths of the minor and major axes of the magnetic field polarization ellipse (see text for details), (d) angle between the wave vector and the ambient magnetic field, and (e) parallel component of the Poynting flux normalized by its standard deviation. White or black lines overplotted on the spectrograms show the local electron cyclotron frequency.

about $15 R_{E}, 13-14^{\circ}$ geomagnetic latitude, and 10:30 Magnetic Local Time (MLT). This spectrogram has increasing time, in UT, plotted on the horizontal axis and frequency, in $\mathrm{kHz}$, on the vertical axis with color indicating power spectral density, in $\mathrm{V}^{2} / \mathrm{m}^{2} / \mathrm{Hz}$. The spectrogram was created by taking 1024 samples of the time series and transforming these data to the frequency domain by using a Fast Fourier Transform. The local electron cyclotron frequency was around $1 \mathrm{kHz}$ as determined from FGM data and the plasma frequency as determined from the Whisper sounder was $35 \mathrm{kHz}$ (shown as an overplotted white line in Fig. 1a, both panels). Thus Cluster is in a weakly magnetized region of space. Figure $1 \mathrm{~b}$ shows a $4 \mathrm{~ms}$ line plot of the waveforms beginning at 03:26:22.181 UT. These waveforms were obtained by WBD on SC4 during the 35-min interval seen in the spectrogram (Fig. 1a, bottom panel). The line plot in Fig. 1b has increasing time, in seconds from 03:26:22.181 UT, plotted on the horizontal axis and electric field amplitude, in $\mathrm{mV} / \mathrm{m}$, plotted on the vertical axis. The total angle of the electric field antenna used by WBD to the local magnetic field using transformed FGM data, in degrees, is shown on the right vertical scale. During the time interval in Fig. 1b, we see that the antenna was nearly aligned with the magnetic field direction. The spectrogram at the time of the waveform in Fig. $1 \mathrm{~b}$ shows only a broadband signal ranging in frequency from the lower cutoff of the filter around $1 \mathrm{kHz}$, where its greatest intensity is observed, up to about $50 \mathrm{kHz}$, where a 
much lower intensity is observed. The broadband signal results from the fact that the pulses observed in the waveforms in Fig. $1 \mathrm{~b}$ contain all frequencies. When one or more of these pulses are dominant in a 1024 point sample and are transformed to the frequency domain via Fast Fourier Transform, the expected result is a broadband signal as observed. Thus, the broadbands seen in Fig. 1a throughout the magnetosheath interval ( 03:20-03:50 UT) indicate that solitary waves are present continuously after crossing the bow shock.

In order to better appreciate the context in which the solitary waves are observed, below we present some Cluster lower frequency wave, particle and magnetic field data for the event highlighted in Fig. 1. We start by showing the wave data in the frequency range of $8 \mathrm{~Hz}$ to $4 \mathrm{kHz}$ obtained by the STAFF-SA instrument on SC4 on 26 March 2002 in Fig. 2. The various panels contain the following: (a) the sum of the power spectral densities of the two orthogonal electric components in the spin plane of the spacecraft, (b) sum of the power spectral densities of the three orthogonal magnetic components, (c) estimate of the ratio of lengths of the minor and major axes of the magnetic field polarization ellipse obtained using the SVD analysis (Santolík et al., 2003), where the sign reflects the sense of polarization with respect to the ambient magnetic field, negative being left-hand and positive right-hand, (d) angle between the wave vector and the ambient magnetic field obtained from polarization of the magnetic field fluctuations using the SVD method, and (e) parallel component of the Poynting flux normalized by its standard deviation. White or black lines overplotted on the spectrograms show the local electron cyclotron frequency. Note that the seeming lack of data above about $100 \mathrm{~Hz}$ in panels (c) through (e) is related to the fact that the analysis is being done with only the magnetic components and a threshold has been set near the noise floor of the receiver to prevent confusing results associated with the analysis of background noise. Panels (a) and (b) clearly show that there are broadband waves, both electric and magnetic, up to about $100 \mathrm{~Hz}$ after the bow shock is crossed at 03:19 UT. Using only the magnetic components from panel (b), there is no consistent polarization of these waves as shown by panel (c), nor is there a consistent wave normal angle (panel d) or propagation direction (panel e), clearly suggesting that these waves are not whistler mode. Not surprisingly, this also suggests that the spacecraft are immersed in a very turbulent medium. On the other hand, short duration whistler mode lion roars begin to appear at about 03:37 UT, identified by their polarization being right-handed and in the frequency range $200-400 \mathrm{~Hz}$ $(0.2-0.4 \mathrm{fce})$. They are at lower wave normal angles $\left(\sim 30^{\circ}\right)$, consistent with the results of Maksimovic et al. (2001), but these angles may be artificially increased by fluctuations of Bo. In addition we can see in panel (c) that they are propagating with a significant parallel component of the Poynting vector. We note that the presence of lion roars may indicate that an electron anisotropy exists (Thorne and Tsurutani, 1981).

We now look at the particle data, beginning with the electrons. Figure 3a covers the same time period as Figs. 1 and

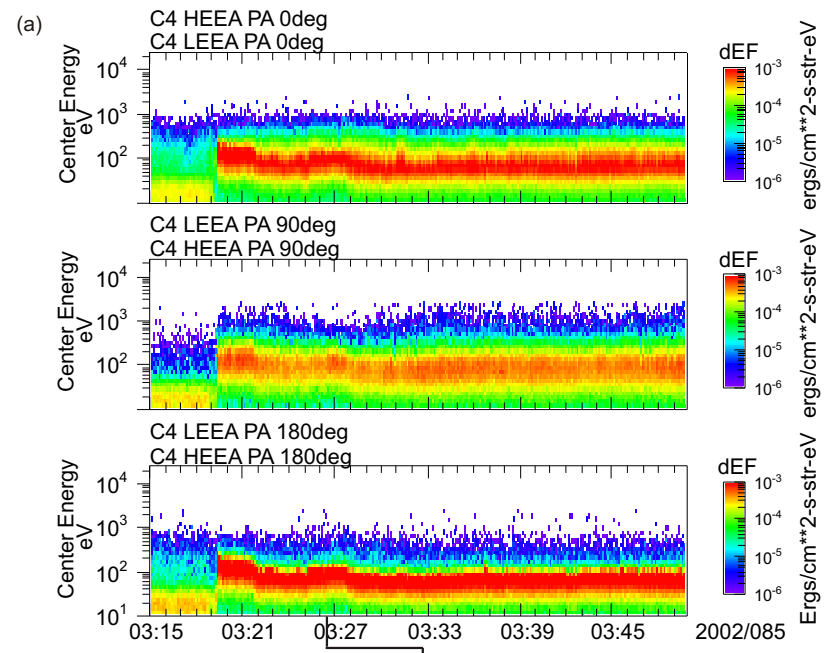

(b)

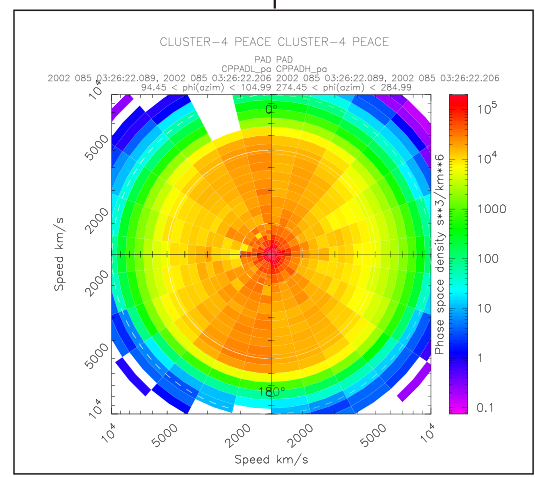

Fig. 3. (a) PEACE energy-time-differential energy flux spectrogram from Cluster 4 showing the flux parallel to the direction of the magnetic field (top panel), perpendicular (middle) and anti-parallel (bottom) for the same time period as Fig. 1. The fluxes in each panel include data from both the LEAA and HEAA sensors. Note the counterstreaming (to $\mathbf{B}$ ) electrons observed in the top and bottom panels at energies around $100 \mathrm{eV}$ and less. (b) Phase-space distribution function collected over a single $(\sim 10 \mathrm{~ms})$ sweep of the sensors obtained from a single spin starting around 03:26:22 UT, the same approximate time as the bipolar solitary waves shown in Fig. $1 \mathrm{~b}$. The left and right hand sides of the polar representation of the distribution function come from the LEAA and HEAA sensors, respectively. This representation as a distribution function assumes gyrotropy. Note that the counterstreaming electrons are observed at velocities on the order of $5000-6000 \mathrm{~km} / \mathrm{s}$ (energies ranging from $10-100 \mathrm{eV})$

2 with PEACE electron data shown only for SC4. In Fig. 3a, the panels, from top to bottom, are the differential energy fluxes according to the color bars on the right observed parallel to $\mathbf{B}$, perpendicular to $\mathbf{B}$, and anti-parallel to $\mathbf{B}$, respectively, form both the LEAA and HEAA sensors of PEACE. The vertical axis contains the center energy scale from $10 \mathrm{eV}$ to $25 \mathrm{keV}$, with time plotted on the horizontal scale. It is evident that the bow shock is crossed at bout 03:19 UT. Once the spacecraft enters the magnetosheath, electrons are seen to be counterstreaming (the top and bottom panels at 0 and $180^{\circ}$ to $\mathrm{B}$, respectively) at energies primarily at or 
Table 1. Magnetosheath solitary wave events included in Fig. 6.

\begin{tabular}{|c|c|c|c|c|c|c|c|}
\hline Date & $\begin{array}{c}\text { Time Period } \\
\text { (UT) }\end{array}$ & $\begin{array}{c}\text { Cluster } \\
\text { Spacecraft }\end{array}$ & $\begin{array}{l}\text { Bipolar Pulses Detected } \\
\text { (Number) }\end{array}$ & $\begin{array}{c}\text { Tripolar Pulses Detected } \\
\text { (Number) }\end{array}$ & $\begin{array}{l}\text { Distance from Earth } \\
\qquad\left(R_{E}\right)\end{array}$ & $\begin{array}{c}\text { Geomagnetic Latitude } \\
\qquad\left(^{\circ}\right)\end{array}$ & $\begin{array}{c}\text { MLT } \\
\text { (hh:mm) }\end{array}$ \\
\hline 29 Jan. 2002 & $\begin{array}{l}10: 59-11: 15 \\
11: 32-12: 15 \\
12: 20-13: 15\end{array}$ & $1,3,4$ & 1188 & 196 & $12.9-11.1$ & -56.4 to -60.4 & $13: 28-13: 02$ \\
\hline 8 Feb. 2002 & 01:15-03:04 & 4 & 478 & 15 & $11.5-9.9$ & -60.5 to -75.0 & $14: 33-15: 36$ \\
\hline 6 Mar. 2002 & $02: 13-04: 20$ & 4 & 792 & 8 & $13.8-12.3$ & -55.9 to -67.1 & $12: 20-12: 00$ \\
\hline 26 Mar. 2002 & $03: 20-03: 50$ & 3,4 & 5050 & 111 & $15.0-15.3$ & 13.8 to 12.4 & $10: 29-10: 30$ \\
\hline 2 Apr. 2002 & 00:00-00:42 & $1,2,4$ & 324 & 24 & $10.0-10.7$ & 45.0 to 39.6 & $09: 33-09: 42$ \\
\hline 22 Apr. 2002 & $15: 55-17: 30$ & 3,4 & 1637 & 22 & $13.8-12.7$ & -40.3 to -48.8 & $09: 15-09: 42$ \\
\hline 13 May 2002 & $\begin{array}{c}15: 50-15: 56 \\
16: 03-16: 24 \\
17: 02-17: 15\end{array}$ & $1,2,3,4$ & 79 & 11 & $18.3-17.9$ & -17.9 to -24.1 & $07: 41-07: 55$ \\
\hline TOTAL & & & 9548 & 387 & & & \\
\hline
\end{tabular}

${ }^{1} 5$ s sampled out of every 52 -s time period

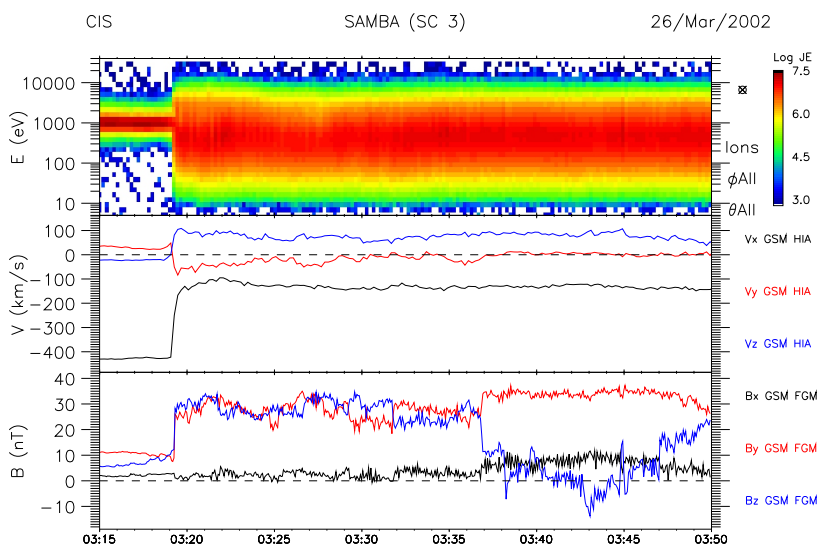

Fig. 4. CIS data (top two panels) and FGM data (bottom panel) from spacecraft 3 for the same time period as Fig. 1 showing the differential energy flux for all ions covering a wide range of energies from about $10 \mathrm{eV}$ up to $10 \mathrm{keV}$ (top panel), the three components of the ion velocity in GSM coordinates (middle panel), and the three components of the magnetic field in GSM coordinates (bottom panel). Note that the direction of the magnetic field changes at about 03:37 UT, but that this has little or no effect on the ion flux or on the waves as observed in Fig. 1.

below $100 \mathrm{eV}$. Some electrons are observed perpendicular to B (middle panel, 90 degree pitch angle), but the flux is weaker. A phase space distribution obtained over a spin period starting at 03:26:22.089 UT, a time that encompasses the observation of the solitary waves seen in Fig. 1b, is shown in Fig. 3b. This representation of the distribution function is constructed from the PAD, or pitch angle data, which is created on-board. To the extent that the distribution function is gyrotropic, PAD data provides a good representation in 2-D of the 3-D distribution. The polar plot goes from field aligned $\left(0^{\circ}\right)$ to backward streaming fluxes at $180^{\circ}$. The left hand side is constructed from LEAA and the right hand side from HEAA. The differences reflect slight differences in calibration as well as differences in the portion of the spin during which data from the two sensors was collected (the two sensors reside on opposite sides of the spacecraft). The differences in azimuth for the two sensors during the collection time are indicated on the plot. PAD data represent a single sweep of the sensors (of order $10 \mathrm{~ms}$ ) with a cadence of $4 \mathrm{~s}$. The electron distribution peaks near 0 and $180^{\circ}$ with velocities of $5000-6000 \mathrm{~km} / \mathrm{s}$. Slices of this distribution at 0 degrees and $90^{\circ}$ show that the counterstreaming in not due to true beams. Beams are sometimes seen close to the bow shock. Nonetheless, one would not expect strong beams to persist, since they should be highly unstable to the excitation of electrostatic waves/structures such as the observed solitary waves. The slice of the distribution function more closely resembles a state of marginal stability, although more analysis would be required to be certain.

The ion data, from the CIS instrument, and magnetic field data, from the FGM instrument, for the same time period on 26 March 2002, but for SC3 as opposed to SC4, are shown in Fig. 4. SC3 was chosen rather than SC4 because the HIA instrument on this latter spacecraft was not operating. Since the spacecraft are only separated by about $100 \mathrm{~km}$ at this time, the ion data from SC3 would be indicative of what is measured on SC4. The panels from top to bottom in Fig. 4 are as follows: 1) Energy-time spectrogram of all ions, with color indicating ion energy flux, 2) ion velocity, in $\mathrm{km} / \mathrm{s}$ with the components $\mathrm{Vx}, \mathrm{Vy}, \mathrm{Vz}$ in the GSM coordinate system plotted in black, red and blue, respectively, with $12 \mathrm{~s}$ resolution, 3) magnetic field, in $\mathrm{nT}$, with the components $\mathrm{Bx}, \mathrm{By}, \mathrm{Bz}$ in the GSM coordinate system in black, red and blue, respectively. The bow shock crossing is quite obvious in all three panels at 03:19 UT with major changes in the character of all data products in the magnetosheath vs. the solar wind. The ions have a broad energy spread, $\sim 10 \mathrm{eV}$ to $10000 \mathrm{eV}$, and are quite intense in the magnetosheath. The ion velocity is greatly reduced in the magnetosheath from that of the solar wind, predominantly directed along the Vx and Vz directions, and the magnetic field strength greatly increases with dominant By and Bz components up to about 03:37 UT, then becoming dominated by the By component. It seems that the appearance of the lion roars around 03:37 UT may be associated with this change in the magnetic field, although there is 

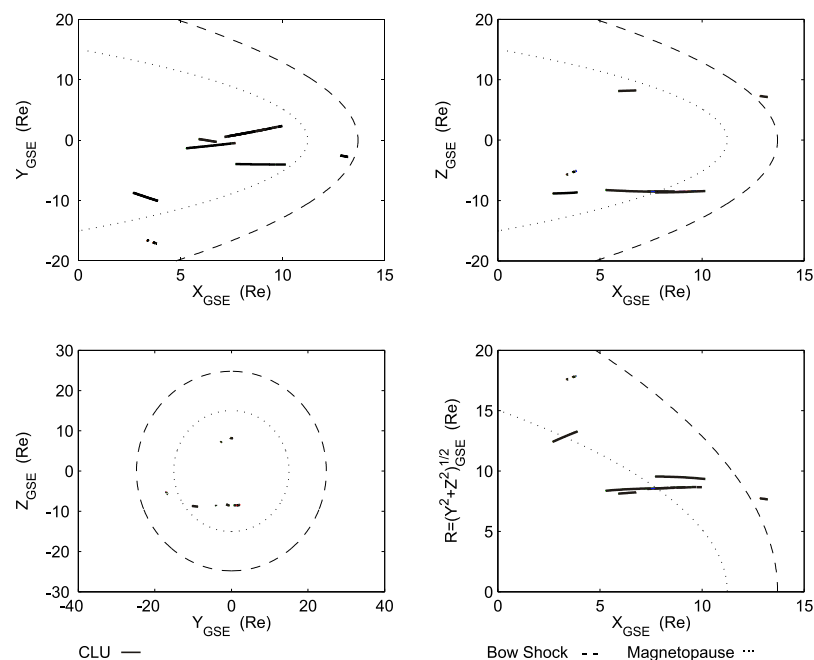

Fig. 5. Location, in GSE coordinates, of the magnetosheath intervals included in the solitary wave survey. See the text for a description of the model bow shock and magnetopause that were used and the explanation for why some intervals appear to lie outside the magnetosheath.

no effect on either amplitudes or time durations of the solitary waves due to the change in the magnetic field direction.

To summarize the event of 26 March 2002, solitary waves with time durations of a few tens to a few hundreds of $\mu$ s and peak-to-peak amplitudes of several hundredths to a few tenths of $\mathrm{mV} / \mathrm{m}$ are seen immediately after crossing the bow shock at about 03:19 UT and continuously for the $30 \mathrm{~min}$ to the end of the provided time period. A substantial amount of electrostatic fluctuations and magnetic turbulence below $100 \mathrm{~Hz}$, counterstreaming electrons below about $100 \mathrm{eV}$, ion fluxes covering a very broad energy range, electron plasma frequency around $35 \mathrm{kHz}$, and magnetic field strength around 35-45 nT are observed during this same 30-min period.

\section{Survey results}

Table 1 presents the time periods over which the primary solitary wave survey was conducted. This table shows the number of unclipped bipolar and tripolar solitary waves observed during each time period, as well as Ephemeris data for each interval. The locations of the Cluster spacecraft in the magnetosheath during the time periods listed in Table 1 are shown in Fig. 5 along with the model bow shock (Cairns et al., 1995) and magnetopause (Sibeck et al., 1991) in a GSE coordinate system. We have used an average solar wind pressure $(1.8 \mathrm{nPa})$ as input to both of these models for all of the events. Thus, the locations of the bow shock and magnetopause as shown in Fig. 5 should be taken as rough estimates of these boundaries only since the solar wind pressure varies across all of our events. We have verified that all of our events lie within the magnetosheath by looking at various Cluster instrument data. For example, the event that looks to be outside the bow shock in Fig. 5 is in fact the event shown
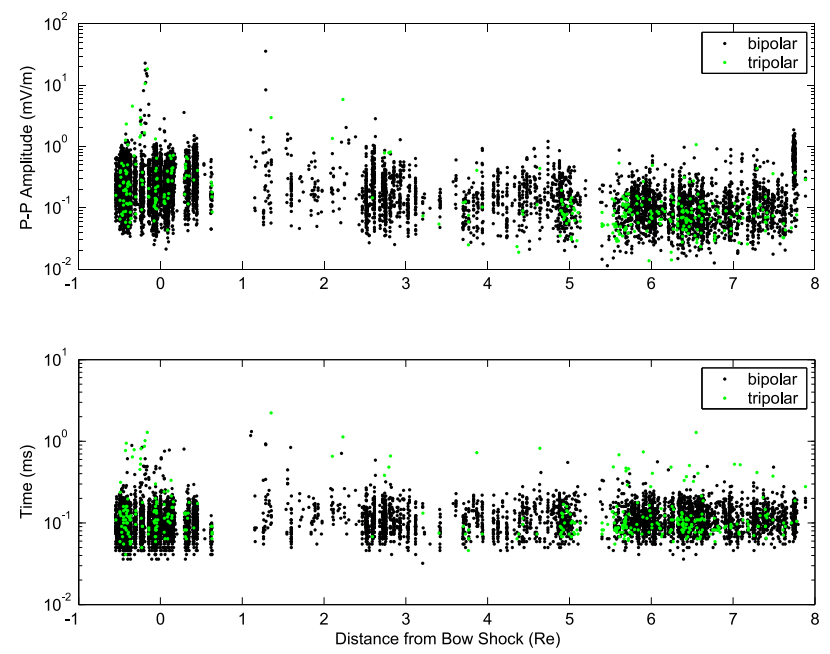

Fig. 6. Characteristics (peak-to-peak amplitude in top panel and pulse duration in bottom panel) of the solitary waves observed during the survey interval as a function of distance from the bow shock, in $R_{E}$. Note that $0 R_{E}$ is the location of the model bow shock, with positive distances lying downstream in the magnetosheath. The points that appear to lie upstream of the bow shock are actually downstream and a consequence of the model not being able to predict the bow shock location to better than $1 R_{E}$. There is no change in either the amplitude or time duration of the solitary waves as the spacecraft get farther from the bow shock.

in Figs. 1 through 4 starting at 03:20 UT, which is clearly inside. Our goal was to choose intervals so as to cover all distances from the bow shock to the magnetopause. For this primary study, we have primarily chosen time intervals in which many solitary waves are observed since our objective is to discover whether the nature of the solitary waves themselves change as the spacecraft travels from the bow shock to the magnetopause. The fact that we can easily find examples of numerous solitary waves at all distances from the bow shock to the magnetopause implies that solitary waves are likely to be found in great numbers anywhere in the nearEarth dayside magnetosheath.

Figure 6 shows the results of our primary survey, that being the amplitudes and time durations of the bipolar solitary waves (black dots) and tripolar solitary waves (green dots) vs. distance from the model bow shock (again using an average solar wind pressure of $1.8 \mathrm{nPa}$ ), 0 being at the bow shock with positive distances being downstream. Distance from the bow shock was determined using the conjugate gradient method and is defined as the minimum distance in threedimensional space between the Cluster spacecraft for which a solitary wave was identified and the three-dimensional surface of the bow shock. In Fig. 6, the amplitude of the detected solitary waves is plotted in a logarithmic scale on the vertical axis (in $\mathrm{mV} / \mathrm{m}$ peak-to-peak) in the top panel and the time duration of the pulses in a logarithmic scale on the vertical axis (in milliseconds) in the bottom panel.

An automatic detection algorithm was used to obtain the times of isolated bipolar and tripolar pulses during only the 
Table 2. Magnetosheath solitary wave events included in Figs. 7 and 8.

\begin{tabular}{|c|c|c|c|c|c|c|c|}
\hline Date & $\begin{array}{l}\text { Time Period } \\
\text { (UT) }\end{array}$ & $\begin{array}{c}\text { Cluster } \\
\text { Spacecraft }\end{array}$ & $\begin{array}{c}\text { Bipolar Pulses Detected } \\
\text { (Number) }\end{array}$ & $\begin{array}{l}\text { Tripolar Pulses Detected } \\
\text { (Number) }\end{array}$ & $\begin{array}{l}\text { Distance from Earth } \\
\qquad\left(R_{E}\right)\end{array}$ & $\begin{array}{l}\text { Geomagnetic Latitude } \\
\qquad\left(^{\circ}\right)\end{array}$ & $\begin{array}{c}\text { MLT } \\
(\mathrm{hh}: \mathrm{mm})\end{array}$ \\
\hline 29 Jan. 2002 & $\begin{array}{l}10: 59-11: 15 \\
11: 32-12: 15 \\
12: 20-13: 15\end{array}$ & 1,3 & 568 & 107 & $12.9-11.1$ & -56.4 to -60.4 & $13: 28-13: 02$ \\
\hline 15 Feb. 2002 & $23: 40-23: 58$ & 1,3 & 28 & 0 & $13.6-13.8$ & 32.9 to 31.0 & $12: 15-12: 16$ \\
\hline 16 Feb. 2002 & $00: 45-02: 35$ & 1,3 & 75 & 6 & $14.3-15.4$ & 26.0 to 16.4 & $12: 20-12: 32$ \\
\hline 26 Mar. 2002 & $03: 20-03: 50$ & 3 & 2570 & 52 & $15.0-15.3$ & 13.8 to 12.4 & $10: 29-10: 30$ \\
\hline 2 Apr. 2002 & $00: 00-00: 42$ & 1 & 94 & 9 & $10.0-10.7$ & 45.0 to 39.6 & $09: 33-09: 42$ \\
\hline 6 Apr. 2002 & $21: 35-23: 30$ & 1,3 & 1230 & 247 & $12.9-14.2$ & 31.7 to 20.5 & $09: 25-09: 37$ \\
\hline 22 Apr. 2002 & $15: 55-17: 30$ & 3 & 727 & 10 & $13.8-12.7$ & -40.3 to -48.8 & $09: 15-09: 42$ \\
\hline 13 May 2002 & $\begin{array}{c}15: 50-15: 56 \\
16: 03-16: 24 \\
17: 02-17: 15\end{array}$ & 1,3 & 42 & 6 & $18.3-17.9$ & -17.9 to -24.1 & $07: 41-07: 55$ \\
\hline TOTAL & & & 5334 & 437 & & & \\
\hline
\end{tabular}

${ }^{1} 5$ s sampled out of every 52 -s time period
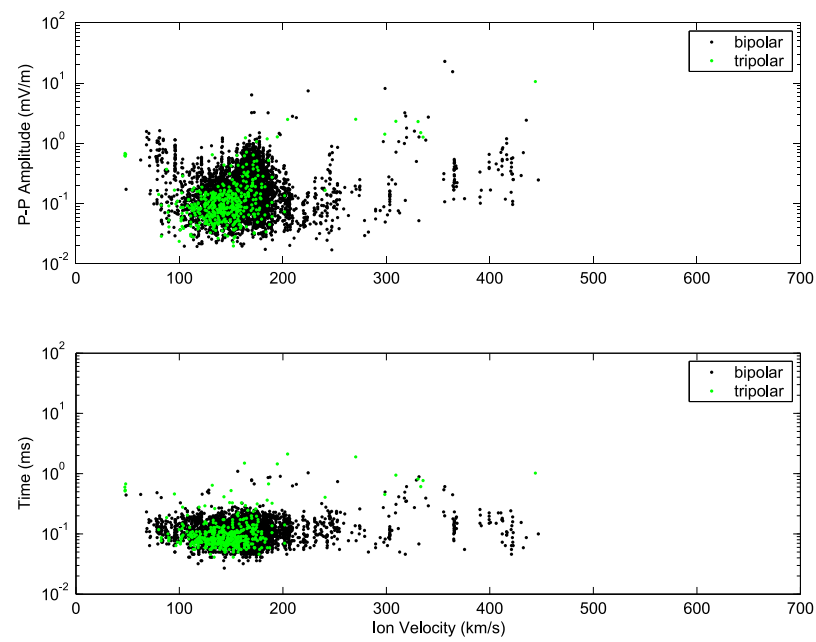

Fig. 7. Characteristics of the solitary waves observed as a function of ion velocity. The format is the same as in Fig. 6. There is no trend for the amplitudes or time durations of the solitary waves to vary based on ion velocity.

first $5 \mathrm{~s}$ out of every 52-s period as described in Pickett et al. (2004b). Any pulse picked up by this automatic detection routine whose waveform was clipped (its amplitude is too large to be resolved within the available dynamic range provided by the gain state) would have been disqualified from being plotted in this survey. On average the percentage of non-clipped pulses to total pulses detected is about $75-85 \%$ in the magnetosheath. Note that the general reduction in solitary wave detections around 0.5 to $2.5 R_{E}$ in Fig. 6 is a result of less WBD data coverage in that region from our chosen events and is thus not physically significant.

It is clear from Fig. 6 that there are solitary waves at all distances and that there is no trend for the amplitudes or time durations to increase or decrease as the spacecraft transit from the bow shock to the magnetopause as might have been expected. Rather, both of these quantities show a tendency to remain constant within a 1-2 order of magnitude window throughout the magnetosheath. A similar result (not shown) to that in Fig. 6 is obtained when we plot the distance from the magnetopause into the magnetosheath. The implication of this is that the solitary waves are being generated locally, but this topic will be discussed later.

Having found that magnetosheath solitary waves are likely to have the same amplitudes and time durations no matter where they are observed in relation to the bow shock, at least for Cluster's orbit in the magnetosheath, we decided to see whether these same two quantities were ordered by either the ion velocity or the angle of the ion velocity to the magnetic field (cone angle). The latter quantity was chosen because in 1994, Coroniti et al. (1994) concluded that the occurrence of the plasma waves from several hundred $\mathrm{Hz}$ to $5 \mathrm{kHz}$ observed by ISEE-3 in the distant magnetosheath are nearly absent when the cone angle is large. To perform this secondary survey, we added some time periods in which very few solitary waves were present and some in which hundreds were present, as shown by Table 2 (same format as Table 1). Figure 7 thus shows the results of the solitary wave amplitude, in the top panel, and pulse duration (bottom panel) on the vertical axis (same format as Fig. 6) vs. the ion velocity obtained by the CIS instrument, in $\mathrm{km} / \mathrm{s}$, on the horizontal axis. There is perhaps a slight tendency for the solitary wave amplitudes to increase with increasing ion velocity, but we do not stress this because ion velocities above $200 \mathrm{~km} / \mathrm{s}$ are less probable. There is certainly no tendency for the time durations of the solitary waves to either increase or decrease with increasing ion velocity. These results thus suggest that ions do not play a singular role, if any, in the generation of the solitary waves.

Figure 8 is the same format as Fig. 7, except that the cone angle, the angle between the magnetic field direction and the ion velocity direction, is plotted on the horizontal axis. Here it is eminently clear that solitary waves are observed at all cone angles with the exception of those around 0 and $180^{\circ}$. These results show that the solitary waves, at least in the near-Earth magnetosheath of Cluster's orbit, are clearly not absent at larger cone angles, nor are they less intense, thus not agreeing with the Coroniti et al. (1994) conclusion. 
We conclude, therefore, that the magnetosheath waves that are nearly absent at large cone angles in the Coroniti et al. (1994) study are waves other than the solitary waves, or that the magnetosheath waves in the distant magnetosheath are much different than those in the near-Earth region. We believe that the former is probably the case, and that it is the waves around a few $\mathrm{kHz}$ (usually less than 5) that are seen in the magnetosheath with the largest intensities that may be the waves that are sensitive to the cone angle. Pickett et al. (2003) found for their magnetosheath case study that the solitary waves seemed to decrease in intensity at large cone angles, but their conclusion was based on assuming an ion velocity direction along $\mathrm{X}_{G S E}$ since ion data were not available. Further, it is clear from the current survey that the solitary wave amplitudes can vary over at least two orders of magnitude at large cone angles, so that the conclusions of Pickett et al. (2003) are not in disagreement with the results shown in Fig. 8 since smaller intensities are allowed at large cone angles. One further trend to note in Fig. 8 is that if solitary waves are present at all, there is a higher probability for them to be observed when the cone angle is around $90^{\circ}$. This may be an effect of the sampling periods used in this survey, i.e., magnetosheath intervals unintentionally weighted towards $90^{\circ}$, or simply due to the fact that for a completely random distribution, the occurrence rate of a cone angle $\alpha$ should be proportional to $\sin \alpha$, so the rate would be small around $0^{\circ}$ and $180^{\circ}$ and large around $90^{\circ}$. This needs to be explored in more depth in future statistical studies.

\section{Analysis and discussion}

We have concluded above, based primarily on the results of Fig. 6, that the solitary waves are most likely being generated locally in the magnetosheath at multiple locations at any point in time. This conclusion is based primarily on the observation that no matter how far away the spacecraft gets from the bow shock or magnetopause, where solitary waves are known to be generated, solitary waves are observed with the same basic characteristics in the magnetosheath. If the solitary waves were being generated at only one or two specific locations, at the bow shock and magnetopause, for instance, and propagating across the magnetosheath, we would expect their characteristics to change since solitary waves are known to be unstable and thus probably incapable of propagating such great distances without growing, decaying or coalescing. This is not a surprising conclusion since the magnetosheath is a turbulent region which implies that local generation of waves is highly probable. Having made this conclusion, it is now necessary to investigate whether any of the supporting data suggest that a local generation mechanism is possible. Since Cluster particle data are not available with the same high time resolution as the waveform data, unlike the FAST mission (e.g., Ergun et al., 1998), it is not possible to associate single isolated solitary wave events with a particular energetic particle flux, whether electron or ion. Thus, we looked at several events where solitary waves are present
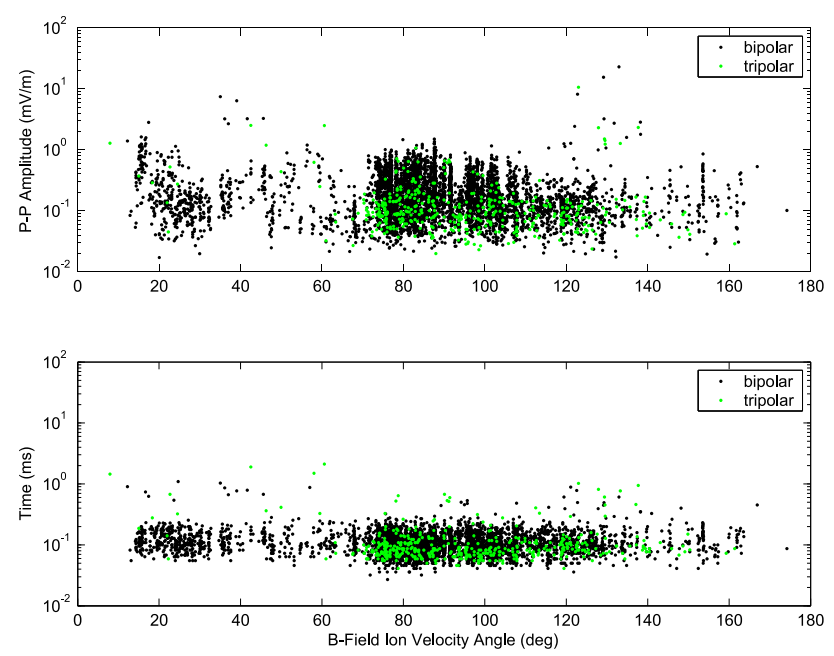

Fig. 8. Characteristics of the solitary waves observed as a function of the angle between the magnetic field and ion velocity directions (cone angle). The format is the same as in Fig. 6. There is no trend for the amplitudes or time durations of the solitary waves to vary based on the cone angle.

most of the time to see if there is a common electron flux or distribution during these times. In addition we looked at a few events where solitary waves are not observed to any great extent to see if we can explain why they are not there. Note that we have excluded ions from this course of investigation since the data presented in the surveys of Figs. 7 and 8 appear to suggest that ions are not singularly involved in the local generation of the solitary waves observed by WBD in the magnetosheath.

Encouraged by the electron data presented in Fig. 3, i.e., the presence of counterstreaming electrons at about 0 and $180^{\circ}$ to $\mathbf{B}$ at or below $100 \mathrm{eV}$, we looked at the electron data from all of the events included in Tables 1 and 2. Table 3 shows the results of this investigation. It is immediately obvious that counterstreaming electrons around $100 \mathrm{eV}$ are present for almost all of the events. For those where they are not present, parts of 2 April 2002 and all of 13 May 2002, for example, solitary waves are still observed but in fewer numbers as noted in Tables 1 and 2. On the other hand for the 15-16 February 2002 event, the counterstreaming electrons are present, yet WBD observes very few solitary waves. We thus look to the magnetic field strength for the answer. For the 15-16 February 2002 event we see that the magnetic field strength is very low for most of the event. Why is this important? Pickett et al. (2004b) showed that there was a general trend for the amplitudes of the solitary waves to increase as the local magnetic field strength increased. Their results show that solitary waves in the magnetosheath are usually not observed below about $10 \mathrm{nT}$ even though solitary waves in the solar wind can be observed down to about $6 \mathrm{nT}$. Does this mean that solitary waves are not generated in the magnetosheath in magnetic fields less than $10 \mathrm{nT}$ ? The answer to this question is that they may be generated in regions of 
Table 3. Local plasma and field characteristics and type of Bow Shock during magnetosheath solitary wave events.

\begin{tabular}{|c|c|c|c|c|c|}
\hline Date & Electrons & $\begin{array}{l}\text { Magnetic Field } \\
\text { Strength } \\
(\mathrm{nT})\end{array}$ & $\begin{array}{l}\text { fce } \\
(\mathrm{Hz})\end{array}$ & $\begin{array}{c}\text { fpe } \\
(\mathrm{kHz})\end{array}$ & $\begin{array}{l}\text { Type of } \\
\text { Bow Shock }\end{array}$ \\
\hline 29 Jan. 2002 & $\begin{array}{l}\text { Counterstreaming at } 0 \\
\text { and } 180^{\circ} \text { to } \mathrm{B} \\
\text { below } 100 \mathrm{eV}\end{array}$ & $21-32$ & $588-896$ & $19-32$ & $\begin{array}{l}\text { Primarily quasi-perpendicular } \\
(\sim 1 / 8 \text { quasi-parallel })\end{array}$ \\
\hline 8 Feb. 2002 & $\begin{array}{l}\text { Observed at } 0,90 \\
\text { and } 180^{\circ} \text { to } \mathrm{B} \text { at similar } \\
\text { flux levels around } 100 \mathrm{eV}\end{array}$ & $13-65$ & $364-1820$ & $23-46$ & Quasi-parallel \\
\hline 15-16 Feb. 2002 & $\begin{array}{l}\text { Similar fluxes at } 0,90 \text { and } 180^{\circ} \\
\text { to } \mathrm{B} \text { at } \sim 100 \mathrm{eV} \text { to } 00: 40, \\
\text { then counter-streaming at } 0 \text { and } 180^{\circ} \\
\text { to } \mathrm{B} \text { below } 100 \mathrm{eV} \text { to end }\end{array}$ & $\begin{array}{l}\text { 6-23, primarily } \\
\text { fluctuating } \\
\text { around } 10\end{array}$ & $168-644$ & $21-41$ & Quasi-parallel \\
\hline 6 Mar. 2002 & $\begin{array}{l}\text { Counterstreaming at } 0 \text { and } \\
180^{\circ} \text { to } \mathrm{B} \text { around } 100 \mathrm{eV}\end{array}$ & $5-35$ & $140-980$ & $15-34$ & $\begin{array}{l}\text { Primarily Quasi-parallel } \\
(\sim 1 / 4 \text { quasi-perpendicular })\end{array}$ \\
\hline 26 Mar. 2002 & $\begin{array}{l}\text { Counterstreaming at } 0 \text { and } \\
180^{\circ} \text { to } \mathrm{B} \text { below } 100 \mathrm{eV}\end{array}$ & $35-45$ & $980-1260$ & $26-37$ & Quasi-perpendicular \\
\hline 2 Apr. 2002 & $\begin{array}{l}\text { Counterstreaming at } 0 \text { and } 180^{\circ} \\
\text { to } \mathrm{B} \text { above } 100 \mathrm{eV} \text { until } 00: 20, \\
\text { then similar fluxes at } 0,90 \text { and } 180^{\circ} \\
\text { at } \sim 100 \mathrm{eV} \text { to end }\end{array}$ & $12-46$ & $336-1288$ & $5-32$ & Quasi-perpendicular \\
\hline 6 Apr. 2002 & $\begin{array}{l}\text { Counterstreaming at } 0 \text { and } 180^{\circ} \\
\text { to } \mathrm{B} \text { below } 100 \mathrm{eV}\end{array}$ & $17-33$ & $476-924$ & $28-40$ & Quasi-parallel \\
\hline 22 Apr. 2002 & $\begin{array}{l}\text { Weak fluxes around } 100 \mathrm{eV} \text { at } 0 \text {, } \\
90 \text { and } 180^{\circ} \text { with stronger } \\
\text { fluxes at } 180^{\circ} \text { around } 16: 35\end{array}$ & $15-27$ & $420-756$ & $15-32$ & Quasi-perpendicular \\
\hline 13 May 2002 & $\begin{array}{l}\text { Observed at } 0,90 \text { and } 180^{\circ} \\
\text { to } \mathrm{B} \text { at similar flux levels } \\
\text { over energy range } 30-150 \mathrm{eV}\end{array}$ & $11-26$ & $308-728$ & $47-58$ & Quasi-parallel \\
\hline
\end{tabular}

magnetic field strength less than $10 \mathrm{nT}$, but due to the overall higher level of turbulence in the magnetosheath over that in the solar wind, it is not possible for our solitary wave detection algorithm to isolate them or distinguish them from other emissions. As further strength to this argument, we note that solitary wave amplitudes at magnetic field strengths below 10 nT, based on Fig. 3a of Pickett et al. (2004b), are expected to be below about $0.05 \mathrm{mV} / \mathrm{m}$, which is near the amplitude level of the other waves and electrostatic fluctuations always observed in the magnetosheath. Thus, we believe that for the 15-16 February 2002 event, even though counterstreaming electrons were observed, WBD failed to measure many solitary waves because the magnetic field strength was too low for much of the event.

Why are the counterstreaming electrons often present in the magnetosheath during solitary wave events? We have briefly looked into this question since it might help in the identification of the generation mechanism of the solitary waves. It has been suggested by Feldman et al. (1983) that a field-aligned electrostatic instability driven by field-aligned electron beams acts to produce the relatively flat-topped electron distribution $\mathrm{f}\left(\mathrm{V}_{/ /}\right)$out to an energy, Eo, usually in the range of 30 to $150 \mathrm{eV}$. There are sometimes two small peaks at the edge of the flat tops making them appear concave up- ward. Gosling et al. (1989) have reported that suprathermal (greater than $\sim 1 \mathrm{keV}$ ) electrons are commonly found downstream from perpendicular and quasi-perpendicular portions of the shock, but not downstream from quasi-parallel portions. Below about $60 \mathrm{eV}$ the distributions for both quasiparallel and quasi-perpendicular were found to be roughly flat-topped, with the phase space density slightly greater for the quasi-parallel shock, while above $60 \mathrm{eV}$ the spectra diverge considerably such that at energies above $\sim 300 \mathrm{eV}$ the electron phase space density for the quasi-perpendicular shock was approximately a factor of 10 higher than that for quasi-parallel shock. This is the motivation for our study of the type of bow shock (determined to first order) which Cluster sits behind during our solitary wave events. The results of Table 3 clearly show that the type of shock has little or no bearing on either the presence of counterstreaming electrons at or below $100 \mathrm{eV}$ or the presence of solitary waves. Another possibility for the presence of counterstreaming electrons in the magnetosheath could lie in the process that Tsurutani et al. (2003) and Lakhina et al. (2004) proposed for a cusp case using Polar data. This proposal suggests that the parallel electric field component of obliquely propagating electromagnetic proton cyclotron waves can provide a mechanism for bi-directional heated electron beams. The 
proton cyclotron waves arise through the loss cone instability as a result of an anisotropy in the particles caused by greater heating of the electrons than ions by phase-steepened Alfvén waves. We are just starting to get results from Cluster that Alfvén waves are present in the magnetosheath (Sahraoui et al., 2003), so it remains to be investigated whether these Alfvén waves are capable of setting in motion the instability needed to create proton cyclotron waves in the magnetosheath, and thus the further instability to create counterstreaming electrons, or whether the Alfvén waves can lead to the generation of the counterstreaming electrons through another method.

Since we have determined that the solitary waves in the magnetosheath are being generated locally, what is the mechanism by which this is possible? It has been shown by several theorists and simulators that electron beam instabilities, of which the two-stream instability is one, can adequately generate solitary waves, usually in the form of electron phasespace holes, with the characteristics of those observed in the magnetotail and auroral acceleration region (e.g., Omura et al., 1996; Goldman et al., 1999; Singh et al., 2000; Newman et al., 2001). Thus, the significant presence of counterstreaming electrons observed in the magnetosheath for most of our events certainly bears investigation as a local source of generation of the solitary waves. Jovanović and Shukla (2004) recently proposed a nonlinear model that provides a theoretical explanation for some of the electrostatic bipolar structures that have been observed in Earth's magnetosheath. This model is based on a drift-kinetic theory for electron phasespace vortices in magnetized space plasmas formulated in the frequency range of the lower-hybrid waves excited by the Buneman instability in the presence of an electron beam. The model accounts for the effects of the electron polarization, anisotropic electron temperature and ion mobility. The quasi-3-D electron holes have the form of either elongated cylinders oblique to the magnetic field, or spheroids. Another possible local generation mechanism that needs to be explored is that of the electron acoustic mode. AshourAbdalla and Okuda (1986) proposed that electron acoustic waves in the distant magnetotail could be produced by an ion beam propagating along the magnetic field in the presence of two populations of electrons (cold and hot). The spectrum of these electron acoustic waves could extend above fpe and appear broadbanded. Dubouloz et al. (1991) also proposed that the high frequency part of the broadband spectrum that extended above fpe and observed on the Viking satellite in the dayside auroral zone could be the result of electron acoustic solitons passing by the satellite. This was a theoretical investigation, but it points to the need to investigate this mode with respect to the solitary waves observed in the magnetosheath by Cluster since their spectral extent often exceeds fpe. Whether a cold electron population necessary to excite electron acoustic solitons is present in the magnetosheath is still under investigation since it is often hard to identify such a population in the electron data in the magnetosheath due to other effects. One final consideration for the local generation of solitary waves involves their spontaneous generation out of the turbulence (Chen et al., 2003) that naturally exists in the magnetosheath. The basis for this spontaneous generation out of turbulence is in part provided by Chen et al. (2004) who obtained a continuum of parameter space for phase-space electron and ion holes (BGK solitary waves). All of these possibilities for the local generation of solitary waves will be explored in greater detail in the future.

\section{Summary}

We have shown above that solitary waves are continuously seen throughout the magnetosheath from the bow shock to the magnetopause, and that the amplitudes and time durations of the solitary waves are about the same no matter how far the spacecraft are from the bow shock at least for Cluster's orbit that encounters the magnetosheath at distances from about $10 R_{E}$ to $19.5 R_{E}$. We interpreted this to imply that the solitary waves are being generated locally in the magnetosheath at multiple locations since we would expect some variance in either the amplitude or time duration, or both, as the spacecraft get farther from the bow shock or closer to the magnetopause (likely sources) since solitary waves are known to be unstable, i.e., they grow and decay and sometimes coalesce over short distances and small time periods. We also concluded that the ions are probably not solely, if at all, responsible for the generation of the solitary waves, as we would have expected there to be a correlation between either the solitary wave amplitudes and time durations and the local ion velocity and there was none.

We concluded that one candidate for the local generation mechanism of the solitary waves was that of the two-stream instability. This is a type of electron beam instability that has been shown to lead to the creation of solitary waves usually in the form of electron phase-space holes. Our conclusion was based on the Cluster observations showing counterstreaming electrons present over long periods of time when solitary waves are observed. We speculated that the reason that solitary waves were not observed during one case where counterstreaming electrons were present was because the background magnetic field strength was too low. At these times, solitary waves might be generated with amplitudes comparable to the background electrostatic fluctuations and other waves, making it impossible to isolate or distinguish the solitary waves. Although we offer the two-stream electron instability as a likely generation mechanism, we do not rule out the possibility that there could be a cold electron component present that when combined with the hot component observed in the magnetosheath could lead to the electron acoustic instability as the generation mechanism. This possibility, as well as one which involves the spontaneous generation out of the turbulence observed in the magnetosheath and one which involves the lower-hybrid Buneman instability in the presence of an electron beam, will be more fully explored in the future. In addition, a more comprehensive statistical study will be carried out that includes many more events with simulations of the counterstreaming electrons to 
see analytically whether they are capable of generating the solitary waves with the characteristics observed.

Acknowledgements. We thank the organizers of the Nonlinear Wave Workshop held in Beaulieu, France in April 2004 for inviting us to present this work. We thank J. Seeberger and J. Dowell at Iowa for processing the WBD data, C. Abramo at DSN and M. Hapgood at JSOC for planning and scheduling the WBD operations, I. Willis and K. Yearby at Sheffield University for the expert commanding of WBD, R. Paredes and the antenna operators at DSN for the successful retrieval of the transmitted WBD data, and everyone at ESOC for the superb operation of the four Cluster spacecraft. Work at the University of Iowa was carried out under NASA GSFC Grants No. NAG5-9974 and No. NNG04GB98G and NSF Grant ATM 03-27450. We also acknowledge the joint Czech Republic/US Grant 0307319/ME 650 from NSF. Portions of this work were carried out at the Jet Propulsion Laboratory, California Institute of Technology under contract with NASA.

Edited by: T. Passot

Reviewed by: two referees

\section{References}

Ashour-Abdalla, M. and Okuda, H.: Electron-acoustic instabilities in the geomagnetic tail, Geophys. Res. Lett., 13, 366-369, 1986.

Balogh, A., Dunlop, M. W., Cowley, S. W., Southwood, D. J., Thomlinson, J., et al.: The Cluster Magnetic Field Experiment, Space Sci. Rev., 79, 65-91, 1997.

Behlke, R., André, M., Bale, S. D., Pickett, J. S., Cattell, C. A., et al.: Solitary structures associated with short large-amplitude magnetic structures (SLAMS) upstream of the Earth's quasiparallel bow shock, Geophys. Res. Lett., 31, 16, L16805, doi:10.1029/2004GRL019524, 2004.

Cairns, I. H., Fairfield, D. H., Anderson, R. R., Carlton, V. E. H., Paularena, K. I., et al.: Unusual locations of Earth's bow shock on Sept. 24-25, 1987: Mach Number affects, J. Geophys. Res., 100, 47-62, 1995.

Cattell, C. A., Dombeck, J., Wygant, J. R., Hudson, M. K., Mozer, F. S., et al.: Comparisons of Polar satellite observations of solitary wave velocities in the plasma sheet boundary and the high altitude cusp to those in the auroral zone, Geophys. Res. Lett., 26, 425-428, 1999.

Cattell, C., Neiman, C., Dombeck, J., Crumley, J., Wygant, J., et al.: Large amplitude solitary waves in and near the Earth's magnetosphere, magnetopause and bow shock: Polar and Cluster observations, Nonlin. Proc. Geophys., 10, 13-26, 2003,

\section{SRef-ID: 1607-7946/npg/2003-10-13.}

Chen, L.-J., Thouless, D. J., and Tang, J.-M.: Width-amplitude relation of Bernstein-Greene-Kruskal solitary waves, http://arxiv. org/abs/physics/0303021, 2003.

Chen, L.-J., Thouless, D. J., and Tang, J.-M.: Bernstein-GreeneKruskal solitary waves in three-dimensional magnetized plasma, Phys. Rev. E, 69, 055402(R), 2004.

Cornilleau-Wehrlin, N., Chauveau, P., Louis, S., Meyer, A., Nappa, J. M., et al.: The Cluster Spatio-Temporal Analysis of Field Fluctuations (STAFF) experiment, Space Sci. Rev., 79, 107-136, 1997.

Coroniti, F. V., Greenstadt, E. W., Moses, S. L., Tsurutani, B. T., and Smith, E. J.: On the absence of plasma wave emissions and the magnetic field orientation in the distant magnetosheath, Geophys. Res. Lett., 21, 2761-2764, 1994.

Décréau, P. M. E., Fergeau, P., Krannosels'kikh, V., Lévêque, M., Martin, Ph., et al.: Whisper, A resonance sounder and wave analyzer: performances and perspectives for the Cluster mission, Space Sci. Rev., 79, 157-193, 1997.

Dubouloz, N., Pottelette, R., Malingre, M., and Treumann, R. A.: Generation of Broadband Electrostatic Acoustic Solitons, Geophys. Res. Lett., 18, 155-158, 1991.

Ergun, R. E., Carlson, C. W., McFadden, J. P., Mozer, F. S., Delory, G. T., et al.: FAST satellite observations of large-amplitude solitary structures, Geophys. Res. Lett., 25, 12, 2041-2044, 1998.

Fairfield, D.: Average and unusual location of the Earth's magnetopause and bow shock, J. Geophys. Res., 76, 6700-6716, 1971.

Feldman, W. C., Anderson, R. C., Bame, S. J., Gary, S. P., Gosling, J. T., et al.: Electron velocity distributions near the Earth's bow shock, J. Geophys. Res., 88, 96-110, 1983.

Franz, J. R., Kintner, P. M., and Pickett, J. S.: POLAR observations of coherent electric field structures, Geophys. Res. Lett., 25, 1277-1280, 1998.

Glassmeier, K.-H., Motschmann, U., Dunlop, M., Balogh, A., Acuña, M. H., et al.: Cluster as a wave telescope - first results from the fluxgate magnetometer, Ann. Geophys., 19, 1439-1447, 2001,

SRef-ID: 1432-0576/ag/2001-19-1439.

Goldman, M. V., Oppenheim, M. M., and Newman, D. L.: Nonlinear two-stream instability as an explanation for auroral bipolar wave signatures, Geophys. Res. Lett., 26, 1821-1824, 1999.

Gosling, J. T., Thomsen, M. F., Bame, S. J., and Russell, C. T.: Suprathermal electrons at Earth's Bow Shock, J. Geophys. Res., 94, 10011-10 025, 1989.

Gurnett, D. A., Huff, R. L., and Kirchner, D. L.: The Wide-Band Plasma Wave Investigation, Space Sci. Rev., 79, 195-208, 1997.

Gurnett, D. A., Huff, R. L., Pickett, J. S., Persoon, A. M., Mutel, R. L., et al: First results from the Cluster wideband plasma wave investigation, Ann. Geophys., 19, 1259-1272, 2001,

SRef-ID: 1432-0576/ag/2001-19-1259.

Jovanović, D. and Shukla, P. K.: Solitary waves in the Earth's magnetosphere: Nonlinear stage of the lower-hybrid Buneman instability, Geophys. Res. Lett., 31, L05805, doi:10.1029/2003GL018047, 2004.

Johnstone, A. D., Alsop, C., Carter, P. J., Coates, A. J., Coker, A. J., et al.: PEACE: A plasma electron and current experiment, Space Sci. Rev., 79, 351-398, 1997.

Kojima, H., Matsumoto, H., Chikuba, S., Horiyama, S., AshourAbdalla, M., et al.: Geotail waveform observations of broadband/narrowband electrostatic noise in the distant tail, J. Geophys. Res., 102(A7), 14 439-14 455, 1997.

Lakhina, G. S., Tsurutani, B. T., and Pickett, J. S.: Association of Alfvén waves and proton cyclotron waves with electrostatic bipolar pulses: Magnetic hole events observed by Polar, Nonl. Proc. Geophys., 11, 205-213, 2004,

SRef-ID: 1607-7946/npg/2004-11-205.

Lepping, R. P., Acuña, M. H., Burlaga, L. F., Farrell, W. M., Slavin, J. A., et al:: The WIND magnetic field investigation, Space Sci. Rev., 71, 207-229, 1995.

Maksimovic, M., Harvey, C. C., Santolík, O., Lacombe, C., de Conchy, Y., et al.: Polarisation and propagation of lion roars in the dusk side magnetosheath, Ann. Geophys., 19, 1429-1438, 2001 ,

SRef-ID: 1432-0576/ag/2001-19-1429. 
McComas, D. J., Blame, S. J., Barker, P., Feldman, W. C., Phillips, J. L., et al.: Solar wind electron proton alpha monitor (SWEPAM) for the Advanced Composition Explorer, Space Sci. Rev., 86, 563-612, 1998.

Newman, D. L., Goldman, M. V., Ergun, R. E., and Mangeney, A.: Formation of double layers and electron holes in a current-driven space plasma, Phys. Rev. Lett., 87 (25), art. no. 255001, 1-4, 2001.

Ogilvie, K. W., Chornay, D. J., Fritzenreiter, R. J., Hunsaker, F., Keller, J., et al.: SWE, a comprehensive plasma instrument for the Wind spacecraft, Space Sci. Rev., 71, 55-77, 1995.

Omura, Y., Matsumoto, H., Miyake, T., and Kojima, H.: Electron beam instabilities as generation mechanism of electrostatic solitary waves in the magnetotail, J. Geophys. Res., 101, 2685-2697, 1996.

Pickett, J. S., Menietti, J. D., Gurnett, D. A., Tsurutani, B., Kintner, P., et al.: Solitary potential structures observed in the magnetosheath by the Cluster spacecraft, Nonlin. Proc. Geophys., 10, 3-11, 2003,

SRef-ID: 1607-7946/npg/2003-10-3.

Pickett, J. S., Kahler, S. W., Chen, L.-J., Huff, R. L., Santolík, O., et al.: Solitary waves observed in the auroral zone: the Cluster multi-spacecraft perspective, Nonlin. Proc. Geophys., 11, 183196, 2004a,

SRef-ID: 1607-7946/npg/2004-11-183.

Pickett, J. S., Chen, L.-J., Kahler, S. W., Santolík, O., Gurnett, D. A., et al.: Isolated electrostatic structures observed throughout the Cluster orbit: Relationship to magnetic field strength, Ann. Geophys., 22, 2515-2523, 2004b,

SRef-ID: 1432-0576/ag/2004-22-2515.

Rème, H., Aoustin, C., Bosqued, J. M., Dandouras, J., Lavraud, B., et al.: First multispacecraft ion measurements in and near the Earth's magnetosphere with the identical Cluster ion spectrometry (CIS) experiment, Ann. Geophys., 19, 1303-1354, 2001,

SRef-ID: 1432-0576/ag/2001-19-1303.
Rodriguez, P.: Magnetosheath electrostatic turbulence, J. Geophys. Res., 84, 917-930, 1979.

Sahraoui, F., Pinçon, J. L., Belmont, G., Rezeau, L., and CornilleauWehrlin, N.: ULF wave identification in the magnetosheath: The k-filtering technique applied to Cluster II data, J. Geophys. Res., 108(A9), 1335, doi:10.1029/2002JA009587, 2003.

Santolík, O., Parrot, M., and Lefeuvre, F.: Singular value decomposition methods for wave propagation analysis, Radio Sci., 38(1), 1010, doi:10.1029/2000RS002523, 2003.

Sibeck, D. G., Lopez, R. E., and Roelof, E. C.: Solar wind control of the magnetopause shape, location, and motion, J. Geophys. Res., 96, 5489-5495, 1991.

Singh, N., Loo, S. M., Wells, B. E., and Deverapalli, C.: Threedimensional structure of electron holes driven by an electron beam, Geophys. Res. Lett., 27, 2469-2472, 2000.

Smith, C. W., Acuña, M. H., Burlaga, L. F., L'Heureux, J., Ness, N. F., et al.: The ACE Magnetic Fields Experiment, Space Sci. Rev., 86, 613-632, 1998.

Thorne, R. M. and Tsurutani, B. T.: The generation mechanism for magnetosheath lion roars, Nature, 293, 384-386, 1981.

Tsurutani, B. T., Smith, E. J., Anderson, R. R., Ogilvie, R. W., Scudder, J. D., et al.: Lion roars and nonoscillatory drift mirror waves in the magnetosheath, J. Geophys. Res., 87, 6060-6072, 1982.

Tsurutani, B. T., Dasgupta, B., Arballo, J. D., Lakhina, G. S., and Pickett, J. S.: Magnetic field turbulence, electron heating, magnetic holes, proton cyclotron waves, and the onsets of bipolar pulse (electron hole) events: a possible unifying scenario, Nonlin. Proc. Geophys., 21, 27-35, 2003. 